\title{
A REgUlaÇÃo NA PUBLICIDAdE DE CERVEJAS JUNTO AO PÚBLICO ADOLESCENTE: PROBLEMÁTICAS E CAMINHOS DA PESQUISA COMUNICACIONAL ${ }^{1}$
}

\author{
Regulation of beers in advertising to the public teen: issues and ways of \\ communication research
}

\section{Regulación en la publicidad de cervezas para los adolescentes: problemas y perspectivas de la investigación en comunicación}

\author{
Eneus Trindade ${ }^{2}$
}

\section{Resumo}

Este trabalho refere-se à discussão sobre as problemáticas de pesquisa do projeto integrado Cerveja, Publicidade, Regulação e Consumo: o olhar da comunicação sobre as marcas de cervejas contemporâneas e suas implicações na vida social de adolescentes, financiado pelo CNPq e realizado no âmbito do GESC3/CNPq/USP. A perspectiva de trabalho conjuga aspectos da regulação e regulamentação do consumo de bebidas alcoólicas, cerveja especificamente, com o estudo de recepção, sobre os conteúdos e os efeitos de impacto de percepção dos elementos das campanhas publicitárias, como também inclui o olhar sobre da circulação de mensagens do setor entre os sujeitos investigados nas mídias sociais. O trabalho busca ainda a análise e crítica da trajetória das marcas de cerveja em seus discursos (conceitos e temas de campanhas). Tal abordagem visa apontar outros caminhos para o debate nacional sobre o assunto.

Palavras-chave: publicidade, marcas, cerveja, regulação, consumo, mediatização.

\begin{abstract}
This article refers about the problems of research about Beer, Advertisement, Regulation and Consumption: the look of communication about brands of beers and its

\footnotetext{
${ }^{1}$ Trabalho originalmente apresentado no III Pró-Pesq PP - Encontro de Pesquisadores em Publicidade e Propaganda. De 24/05/2012 e 25/05/2012 no CRP/ECA/USP.

${ }^{2}$ Professor Livre-Docente do Curso de Publicidade e Propaganda da ECA/USP, Vice-coordenador do PPGCOM/USP, Líder do Grupo de Estudos Semióticos em Comunicação, Cultura e Consumo (GESC3/ CNPq/USP) e Presidente da ABP2- Associação Brasileira de Pesquisadores em Publiciadade.
} 
A regulação na publicidade de cervejas junto ao público adolescente: problemáticas e caminhos da pesquisa comunicacional

de Eneus Trindade

implications for contemporary social life of teenagers, funded by $\mathrm{CNPq}$ and conducted under the GESC3/CNPq/USP. The prospect of work combines aspects of regulation and regulation of alcoholic beverages, specifically beer, with the reception study on the content and effects of impact perception of the elements of advertising campaigns, but also includes the view on the movement of messages sector among subjects investigated in social media. The study also seeks to analyze and critique the trajectory of beer brands in their speeches (concepts and themes of campaigns). This approach aims to point to other ways to the national debate on the subject.

Keywords: advertising, brands, beer, regulation, consumption, mediatization.

\section{Resumen}

Este trabajo se refiere a la discusión sobre los problemas de diseño de la investigación integrada Cerveza, Publicidad, Regulación y Consumo: el aspecto de la comunicación acerca de las marcas de cervezas y sus implicaciones en la vida social contemporánea de los adolescentes, operada con fondos de CNPq y realizada bajo el GESC3/CNPq/USP. La perspectiva de trabajo combina aspectos de la regulación de comunicación y la regulación del consumo de las bebidas alcohólicas, especialmente cerveza, con el estudio de recepción en el contenido y los efectos de la percepción del impacto de los elementos de las campañas de publicidad, sino que también incluye la opinión sobre el movimiento de mensajes de este sector entre los sujetos investigados en los medios sociales. El estudio también pretende analizar y criticar la trayectoria de las marcas de cerveza en sus discursos (conceptos y temas de campañas). Este enfoque tiene como objetivo apuntar a otras perspectivas para el debate nacional del tema.

Palabras-clave: publicidad, marcas, cerveza, regulación, consumo, mediatización.

\section{INTRODUÇÃO}

Este trabalho refere-se à discussão da problemática do projeto integrado Cerveja, Publicidade, Regulação e Consumo: o olhar da comunicação sobre as marcas de cervejas contemporâneas e suas implicações na vida social de adolescentes, financiado pelo CNPq. A perspectiva de trabalho conjuga aspectos da regulação e regulamentação do consumo de bebidas alcoólicas, cerveja especificamente, com o estudo de recepção, sobre os conteúdos e os efeitos de impacto de percepção dos elementos das campanhas 
A regulação na publicidade de cervejas junto ao público adolescente: problemáticas e caminhos da pesquisa comunicacional

de Eneus Trindade

publicitárias, como também inclui o olhar sobre da circulação de mensagens do setor entre os sujeitos investigados nas mídias sociais. O trabalho busca ainda a análise e crítica da trajetória das marcas de cerveja em seus discursos (conceitos e temas de campanhas). Tal abordagem visa conhecer os processos de mediatização e presença das marcas de cerveja na vida dos adolescentes que vivem em São Paulo, pelo olhar da pesquisa em Comunicação, tendo em vista que o assunto é estudado pela área de Saúde Pública e do Direito, mas é pouco abordado, do modo como se pretende aqui, no campo das Ciências da Comunicação. Esta pesquisa visa gerar outros pontos de vista para o debate nacional sobre o assunto.

A pesquisa nasce do interesse de três docentes do Departamento de Relações Públicas e Turismo da Escola de Comunicações e Artes da Universidade de São Paulo, ligados à linha de pesquisa Consumo e usos midiáticos nas práticas sociais, do PPGCOM/USP e que se integram ao Grupo de Estudos Semióticos em Comunicação Cultura e Consumo GESC3/USP/CNPq, para estudar os fenômenos da mediatização e miditização dos discursos das marcas de cerveja entre adolescentes da cidade de São Paulo.

Tal recorte, por si só, já demonstra coesão e coerência institucional com a linha e grupo de pesquisa onde o projeto se insere. De outro lado, a temática em pauta tornouse oportuna ao se perceber que a maioria dos estudos desta natureza, como aponta publicação de Ilana Pinsky (2009), está associado à produção científica de áreas como o Direito e Saúde Pública.

Existe na atualidade uma grande preocupação social em relação ao consumo de bebidas alcoólicas por adolescentes. Percebe-se nos estudos das áreas de Saúde e Direito que, embora o consumo de bebidas alcóolicas por menores de idade seja contrário às leis vigentes no país, que só permitem o consumo deste tipo de bebidas por maiores de 18 anos, é notório o desrespeito a esta lei por praticamente todas as camadas da população; desde pais que estimulam seus filhos a bebericar em festas e confraternizações que envolvem adultos, bares que não se preocupam em saber para quem estão vendendo a bebida, até festas de adolescentes patrocinadas por indústrias de cerveja (e outras bebidas) ou mesmo pelos próprios pais que incluem bebidas alcoólicas de todo tipo em aniversários e comemorações de seus filhos menores de idade. Ver Pinsky (2009: 11-14). 
A regulação na publicidade de cervejas junto ao público adolescente: problemáticas e caminhos da pesquisa comunicacional

de Eneus Trindade

A cerveja, no conjunto de bebidas alcóolicas, não sofre restrições para apresentação de suas propangandas no Brasil, referentes à Lei 9.294 de 1996 que considera bebida alcóolica apenas os produtos a partir de $13^{\circ} \mathrm{G}$ de concentração de álcool. Isso a exclui destas restrições e suas mensagens publicitárias podem ser veículadas em qualquer horário, submetendo indivíduos fora da condição legal de consumo à exposição frequente de mensagens inadequadas.

Nesse sentido, o projeto proposto busca, portanto, um aprofundamento no entendimento das relações sociais de jovens adolescentes permeadas pelo consumo de cerveja e intermediadas pela propaganda comercial e de suas formas de publicização nas mídias tradicionais e mídias sociais.

Sem menosprezarmos e reconhecendo as bases que os estudos feitos nas áreas de Saúde e do Direito nos oferecem, percebemos que muito deles chegam a conclusões semelhantes e, muitas vezes, com interpretações reducionistas sobre os efeitos das mídias no consumo de álcool que se revelam nas seguintes postulações: deve haver maior estímulo às campanhas de incentivo à prenvenção ao consumo de álcool; deve haver um maior controle no acesso à compra de bebidas alcóolicas, sobretudo, no que diz respeito à impossibilidade de venda aos menores de idade; controle do processo de divulgação, com restrição de horários, locais e dos tipos de divulgação das marcas de bebidas alcóolicas, neste caso sugere-se muitas vezes, num discurso em prol da saúde pública, a proibição da veiculação de campanhas. (PINSKY, 2009).

Todavia, tais discursos não consideram o sentido cultural que a mídia ou seu processo de mediatização traz para construção de referências culturais nas práticas de consumo, por meio de suas práticas de interação, sugerindo resoluções que nem sempre neutralizam o processo de discursivização social já implementado por estas marcas de bebidas/cervejas, pois existem várias formas de divulgação (publicização), como diria Casaqui (2011) para além da publicidade em si em seus formatos tradicionais. Por esta razão, torna-se necessário trazer à cena o olhar comunicacional sobre o assunto, cuja representação nas discussões tem se dado por profissionais da área, que não são pesquisadores e que tem interesses próprios na circulação de mensagens desta categoria de produto em estudo, visto que as marcas de cervejas estão entre os princiais anunciantes no contexto nacional.

Segundo, Pinsky (2009: 17) repaldada em vários estudos nacionais (PINSKY e PAVARINO, 2007); (PINSKY e JUNDI, 2008); (PINSKY e SILVA, 1999); 
A regulação na publicidade de cervejas junto ao público adolescente: problemáticas e caminhos da pesquisa comunicacional

de Eneus Trindade

(VENDRAME, PINSKY, FARIA e SILVA, 2008) e internacionais (AUSTIN e HUST, 2005); (AUSTIN, CHEN, GRUBE, 2006); (SAFFER, 1991); (SAFFER e DAVE, 2006); (SNYDER, MILICI, SLATER, SUN, STRIZHAKOVA, 2006); (COLLINS, ELLICKSON, McCAFREY, 2007); (ELLICKSON, COLLINS e HAMBARSOOIANS, 2005); (HASTINGS, 2000); (HASTINGS, ANDERSON, COOKE e GORDON, 2005); (GRUBE, 2000), realizados nos últimos 20 anos, a publicidade de bebidas alcóolicas seria a causadora: de reforçar atitude pró-álcool; podendo reforçar o aumento de consumo de quem já bebe; podendo desestimular a redução do consumo de álcool; influencia a percepção dos jovens sobre o àlcool e as normas para beber, o que predispõe os jovens a querer beber antes do 18 anos.

A pesquisadora também considera neste processo que existem determinantes socioculturais como tolerância ao consumo de àlcool; influência de amigos e familiares que consomem àlcool e estimulam os jovens. (PINSKY, 2009: 15).

O problema de saúde pública sobre o consumo de álcool por menores de idade fica evidente a partir de uma série de ações que vão desde como o jovem bebe, pela caracterização do fenômeno binge (encher a cara) e os problemas de alcoolismo precoce e os acidentes e mortes por eles causados. Em estudos sobre o assunto fica patente a influência da publicidade. (PINSKY, 2009: 7-9).

Pinsky considera sobre os resultados de tais estudos as seguinte postulações: deveria haver um aumento de impostos sobre as bebidas e uma completa proibição das campanhas de bebidas alcóolicas. Esse seria o caminho mais eficaz, segundo a pesquisadora para diminuir o consumo de àlcool entre jovens. A publicidade atingiria o jovem em três formas: pela exposição frequente às mensagens; pela resposta afetiva (quando os jovens são atraídos pela publicidade e gostam dos comerciais) e pela lembrança (quando os jovens se recordam da propaganda, o que está diretamente ligado ao quanto eles gostam de uma mensagem). (PINSKY, 2009: 29).

Mas frente à problemática instalada, não existem discussões de como a cerveja, por meio da comunicação se faz presente na vida dos adolescentes, pois além da presença da comunicação, há a presença e sociabilização desses adolescentes pelo consumo de bebidas alcóolicas.

Nesse sentido, cabe acrescentar que junto a esta reflexão maior, será realizado o estudo dos rituais de consumo da cerveja. Isto é, análise das práticas de consumo sugeridas nas propagandas televisivas e de revistas no período de 2008-2011, que busca 
A regulação na publicidade de cervejas junto ao público adolescente: problemáticas e caminhos da pesquisa comunicacional

de Eneus Trindade

compreender em conexão com as raízes históricas das práticas alimentares em torno da cerveja como uma prática social e não apenas com foco nos seus efeitos junto ao corpo e à saúde, bem como a análise dos conteúdos referente a esta temática no universo das mídias social facebook, twitter, entre outros, para perceber como se dá a circulação de sentidos dos discursos dos adolescentes nestas mídias sobre esta temática.

A reflexão ora em pauta tem como objetivo realizar a análise de discurso crítica das campanhas de cerveja entre 2008 e 2011, com vista à crítica ao processo de mediatização gerado por este setor na vida social e suas consequências, entre elas o estímulo ao consumo de álcool por menores de 18 anos. Isto é, busca-se compreender a regulação de sentido discursivos das comunicações do setor cervejeiro junto ao público adolescente.

Assim, o projeto integrado em proposição ganha relevância na sua linha de pesquisa, por trazer o olhar das Ciências da Comunicação para este cenário de discussões, pois analisa o sentido mediatizado e midiatizado no consumo de bebidas alcoólicas e suas consequências para o âmbito do convívio social, principalmente em se tratando das mudanças que ocorreram predominantemente no Pós-Revolução Industrial e que clamam por tranformações, em função do cenário regulador, para controlar o consumo e a ansiedade dos setores produtivos de mercado, quando se constata os números alarmantes, referentes aos problemas de saúde pública causados por acidentes de trânsito motivados pelo consumo de bebidas alcóolicas, muitas vezes personalizado no consumo de cerveja em exagero. Isso aponta para uma contribuição possível que a comunicação pode e deve oferecer na busca de alternativas para a prática responsável de consumo de bebidas alcóolicas.

No cenário atual, vários organismos da sáude e da regulação como a ANVISAAgência Nacional de Vigilância Sanitária ${ }^{3}$ criada pela Lei Federal 9782 de 1999 discutem a possibilidade de proibição das campanhas de cerveja, pois dentro do marco regulador os interesses da sociedade devem ser preservados acima dos interesses comerciais e o consumo de álcool/cerveja por menores, como temos visto, já demanda a atenção da opinião pública e do Ministério da Saúde.

\footnotetext{
${ }^{3}$ As agências reguladoras surgem no período de gestão do Presidente Fernando Henrique Carodoso. A ANVISA é neste sentido, o órgão regulador do Ministério da Saúde do Brasil responsável pelo controle sanitário de todos os produtos e serviços submetidos à vigilância sanitária (medicamentos, alimentos, produtos de limpeza entre outros) além de ser a responsável pela aprovação da produção e comercialização de tais produtos.
} 
A regulação na publicidade de cervejas junto ao público adolescente: problemáticas e caminhos da pesquisa comunicacional

de Eneus Trindade

Mas um órgão regulador, nem sempre consegue atuar impondo regulamentações, que possuem força de lei, e as fragilidades de processo regulatório ficam evidentes. Disso surge a questão: em que medida a sociedade brasileira e suas instituições, sobretudo comerciais, reconhece a importância do marco regulatório?

Nesse processo, torna-se patente a confusão entre regulação e regulamentação. A regulação seria um processo maior de gestão do interesse público, a partir da oferta de produtos, serviços de um dado setor, implicando em regulações do consumo, econômicas, de saúde pública e da comunicação deste setor.

As empresas não podem oferecer só o que lhes é conveniente. Tal setor seria regulado por uma ou mais das várias agências nacionais de regulação existentes, que podem fazer uso, como órgão regulador, da apresentação de normas/práticas para a área e de regulamentações, que, neste último caso, podem e devem adquirir força de lei para garantir os interessses sociais comuns e não só os dos empresários do setor.

Há também o CONAR - Código de Autorregulamentação Publicitária, òrgão não-governamental instituído por representantes do setor (agências, veículos, anunciantes e membros da sociedade civil) que busca gerar normas e restrições às campanhas de comunicação nas mídias. A atuação do CONAR tem sido bastante questionada quanto ao assunto em pauta e também de outras áreas do consumo. Seja pelo fato de ser um órgão autorregulamentador, representado por interesses de publicitários e de anunciantes, o que por si só já é um desvio do princípio das políticas de regulação que visam o interesse público, pois um setor não pode se autorregular em prol do seu próprio interesse; seja pelo fato de não ter força de lei; e ainda, seja pela sua fragilidade de fiscalização, pois as ações do CONAR se desenvolvem por denúncias e processos que não atendem a demanda imediata das reinvidicações dos seus reclamantes.

Essa atuação frágil do CONAR fica demonstrada em estudo desenvolvido por (VENDRAME, PISNKY, SILVA e BABOR, 2007/2008), que perceberam entre cinco propagandas de cerveja, indicadas como mais atraentes por adolescentes de 15 a 17 anos investigados que, das 16 normas do CONAR, 11 haviam sido violadas nas cinco mensagens. E nenhuma delas sofreu qualqueral tipo de denúncia ou processo pelo referido órgão.

Portanto, percebe-se que o tema traz conflitos de interesses, aborda questões da comunicação comercial e da comunicação do risco sobre consumo de bebidas alcóolicas 
A regulação na publicidade de cervejas junto ao público adolescente: problemáticas e caminhos da pesquisa comunicacional

de Eneus Trindade

e demanda atenção da Comunicação, do Direito e da Saúde Pública. Hoje, se discute a necessidade de regulamentar a proibição de campanhas de cervejas junto aos meios de comunicação. O CONAR é contra, por razões óbvias dos interesses das Agências e dos anunciantes, que são um dos principais investidores na atividade publicitária no país, argumentando que tal proibição fere o princípio de "Liberdade de expressão". Mas O limite da liberdade de expressão esbarra neste caso com um problema de Saúde Pública.

Os estudos no Direito e na Saúde Pública encaminham, na sua maior parte, para a probição da publicidade. Mas qual o fundamento comunicacional para isso? O que estas áreas do conhecimento entendem por publicidade, numa era de grandes trasnformações midiáticas e do surgimetno de novas formas de comunicação que publicizam marcas? Em que medidas as práticas legais utilizadas nos últimos anos tem se mostrado eficientes para regular os discursos das campanhas de cerveja? Como o discurso da comunicação pode operar para as práticas de consumo responsável de bebidas alcóolicas?

A reflexão sobre a tais questões tornam necessária a crítica aos discursos dessas campanhas de cervejas para promover, por meio das práticas discursivas midiáticas, as práticas sociais responsáveis referentes ao consumo de àlcool. Tal perspectiva tem estado fora desta discussão. E soma-se a esta problemática o fato de que tendo como base vários estudos publicados sobre o tema, que colocam a propaganda de cerveja como um grande vilão deste comportamento, entede-se que se torna relevante avaliar os elementos de atração contidos nas propagandas de cerveja a partir de experimentações laboratorias de percepção, como veremos mais adiante nos próximos itens deste projeto. Assim, busca-se lançar o olhar da Comunicação para o debate acerca do tema.

Para tanto, indicamos os seguitne objetivos para esta pesquisa:

Em uma perspectiva mais geral, o projeto pretende lançar o ponto de vista das Ciências da Comunicação para o enriquecimento do debate público sobre regulação e regulamentação do consumo de bebidas alcóolicas, cerveja em específico, tendo em vista que a área neste debate, só tem sido representada pelos profissionais da publicidade, cujas opiniões são balizadas por interesses de mercado e não em função das pesquisas da Comunicação, inclusive tais pesquisas 
A regulação na publicidade de cervejas junto ao público adolescente: problemáticas e caminhos da pesquisa comunicacional

de Eneus Trindade

podem servir como possibilidades de apresentação de alternativas que contemplem os vários interesses sociais;

Entender como foram construídas as manifestações de sentido da cerveja no Brasil, tanto na perspectiva histórica - evolução da função, usos e consumo - quanto comunicacional; Construir o universo de sentido da cerveja no Brasil a partir da análise das recorrências sígnicas: Quais são as cores utilizadas? Quais são os ícones mais evidentes? Como são construídos os contextos? Quais são os conceitos mais associados? Mapear as manifestações publicitárias das principais marcas de cerveja que estão no Brasil, por meio dos anúncios publicitários impressos e audiovisuais. Analisar as diferentes expressões das marcas de cerveja, tais como, nome, embalagem, rótulo, material de ponto de venda etc. com vistas a compreender a potencialidade comunicativa de cada uma delas. Isto é entender o Universo sígnico do sistema publicitário de cervejas;

Desenvolver uma análise de discurso crítica (ADC) de propagandas veiculadas na televisão, referentes a diversas marcas de cerveja consumidas nacionalmente, como é o caso de Brahma, Skol, Antártica, Kaiser, entre outras. E também em revistas de maior tiragem, representantes de um potencial maior de estímulo ao consumo, como é o caso de Veja e Época, no período de 2008 a 2011, para avaliar os tipos de práticas sociais de consumo sugeridos (seus rituais), manifestados pelas práticas discursivas instituídas pelas campanhas publicitárias. Isto é, avalia a regulação possível de sentidos dos discursos das campanhas frente às suas potencialidades na recepção e circulação;

Observar e comparar os mecanismos de regulação e regulamentação do consumo de bebidas alcóolicas do Brasil com os de outros países (América do Norte e Comunidade Européia), sobretudo, no que se refere aos limites impostos à comunicação publicitária;

Realizar um estudo exploratório de recepção e dos efeitos, por meio de grupo de discussão e monitoramento do impacto e insidências dos olhares, com grupo de adolescentes, de 15 a 17 anos, da Rede Estadual do Ensino Público da cidade de São Paulo. Os estudos de impacto e percepção buscam através de técnicas avançadas de avaliação de foco de atenção (e.g. eye tracker) e de respostas emocionais (e.g. condutância da pele), entender quais elementos contidos nestas propagandas exercem maior atração e emoção nos adolescentes. Esses resultados serão conciliados com os 
A regulação na publicidade de cervejas junto ao público adolescente: problemáticas e caminhos da pesquisa comunicacional

de Eneus Trindade

resultados obtidos por meio da análise discursiva da produção de sentido das propagandas de cervejas no Brasil. Indivíduos serão expostos a algumas propagandas de cerveja, proibidas e não proibidas, buscando subsídios para a relação dos efeitos de determinados conteúdos contidos nas propagandas e a atitude ou a intenção de consumir cerveja em determinadas ocasiões. A proposta de incluir propagandas proibidas e não proibidas permite fornecer subsídios aos órgãos reguladores, principalmente o CONAR, para tecerem considerações às sansões impostas, uma vez que se avalia a resposta da população que se deseja proteger. Medidas comportamentais relacionadas à intenção de consumo além de reconhecimento e recall de aspectos específicos das propagandas fazem parte do método desta etapa da pesquisa. Além disso, o processamento neural das peças publicitárias poderá ser também avaliado, com o uso de técnicas mais avançadas (mas muito mais dispendiosas) como eletroencefalografia (EEG) ou ressonância magnética funcional (FMRI), dependendo das parcerias de colaboração disponíveis. Para estes estudos será necessário adquirir um equipamento de Eye-tracker (ou rastreador de olhos) que deverá custar em torno $\mathrm{R} \$ 12.000,00$ dependendo da qualidade e capacidade do aparelho e seus complementos como capacete, software e computador. Trata-se também de identificar pelos estudos dos conteúdos das mídias sociais, estudos de circulação transmidiáticos, nas relações facilitadas por estes novos meios de comunicação, como os jovens tratam do tema nas suas conversações e interações diretas com amigos. Dada a importância deste meio na comunicação deste segmento da população, acreditamos ser esta etapa extremamente informativa e fornecedora de insumos para análise consolidada da pesquisa. Sendo este um meio novo e que demanda técnicas específicas de análise, a proposta inclui a análise de conteúdo quantitativa combinada com a análise crítica do discurso, buscando gerar um aprofundamento do entendimento das relações do adolescente com a bebida em ambientes de interação social baseado em conversações. Serão observados mídias como o Facebook, o Twitter, Orkut e outras que permitam a análise da interação entre jovens nestes novos espaços de comunicação interativa. Buscar constituir uma possível crítica reguladora dos discursos com vistas às práticas de consumo responsáveis junto ao setor cervejeiro.

\section{QUADRO TEÓRICO DE PARTIDA}


A regulação na publicidade de cervejas junto ao público adolescente: problemáticas e caminhos da pesquisa comunicacional

de Eneus Trindade

Ao se considerar em um sentido mais abrangente deste estudo que o consumo de cerveja compreende uma prática histórica da vida material como definiu Braudel (1961), a alimentação, é necessário que se tenha em mente o quadro histórico da evolução dos hábitos à mesa, para então se especificar a importância que as bebidas alcoólicas tomaram nesse ritual, passando não só a desempenhar uma função biológica, mas também a de representar estratos sociais: aquele que consome determinadas bebidas adquire importância, status.

Assim, autores como Flandrin e Monatanari (1996) fazem uma abordagem da alimentação ao longo da história, referenciando passagens que vão desde a Era PréHistórica aos tempos Contemporâneos. Referência importante para a conceituação dos hábitos alimentares em diferentes povos e nações, que culminam hoje numa generalização predominantemente Ocidental das práticas comensais, refletindo um quadro social diverso e rico, como o fenômeno da mundialização da cerveja.

Carneiro (1998: 5) também conceitua a alimentação no âmbito social a fim de revelar as consequências e características a que a sociedade passa quanto ao ritual nutricional, pois "o que se come é tão importante quanto quando se come, onde se come, como se come e com quem se come." Daí a importância de se entender a penetração da cerveja na vida cotidiana das culturas, a exemplo do contexto brasileiro.s

A partir das bases da alimentação, podemos desenvolver argumentos para a análise das peças publicitárias impressas e televisivas que para tanto necessitam de autores que indiquem os preceitos necessários para investigação sígnica e discursiva, aqui contextualizados em dois blocos:

Primeiramente, no âmbito das potencialidades sígnicas de sentido, tal perspectiva, neste projeto, aboradará o estudo das tendências da comunicação do setor cervejeiro, a partir do seu monitoramento midiáticos nos meios impressos e eltrônicos, bem como de sua performance nos pontos de venda. Para tanto serão usados autores da análise semiótica elaborada por Charles Sanders Peirce (1977) e sua aplicação às marcas e à publicidade como operam (SANTAELLA, 2002) e (PEREZ, 2004). Tais aplicações consideram as dinâmicas do signo e sua semiose no que se refere: às suas manifestações do signo em relação a si mesmo (suas qualidades, singularidades e convencionalidades); do signo em relação ao objeto que prepresenta e do signo em relação às suas potencialidades de sentido, os interpretantes possíveis a serem gerados por seus intérpretes. 
A regulação na publicidade de cervejas junto ao público adolescente: problemáticas e caminhos da pesquisa comunicacional

de Eneus Trindade

Em outro momento de análise dos discursos midiáticos da publicidade e dos estudos de recepção sobre tais discursos, serão usados autores da análise de discurso crítica, formulada por Fairclough (2001 e 2003) e Chouliariki e Fairclough (1999), pois esta vertente dos estudos dos discursos possibilita a análise da dimensão representacional com suas ideologias, sentidos e hegemeonias; da dimensão identificacional que constiui os processos de identificação dos discursos com os sujeitos na vida social; e a dimensão acional que mostra como os dicursos se revelam enquanto práticas sociais, nas ações textuais dos sujeitos. Trata-se de buscar entender os processos da discursivização social.

Além destes, tornam-se oportunas as discussões sobre mediatização e midiatização como formas de estabelecimentos das práticas interacionais estabelecidas pelas mídias e de suas possibilidades na contrução de referências no âmbito das culturas como discute Braga (2006), que no caso da publicidade e das marcas, encontram tais manifestações sintetizadas por aquilo que Vander Casaqui (2011) denomina como formas de publicização. Isto é, formas de comunicação marcárias que não se restringem aos formatos publicitários tradicionais, mas que servem de igual modo ao funcionamento da dinâmica comunicacional das marcas para a constituição dos vínculos de sentidos entre produtos/marcas e seus consumidores, a exemplo da discussão de Di Nallo (1999) sobre os meeting points ou pontos de contatos, que se dariam na compreensão das situações de consumo projetadas nas comunicações publicizadas.

Percebe-se que o sentido de mediatização se dá num mecanismo amplo de regulação dos sentidos discursivizados socialmente pelos meios e circustâncias de suas possíveis recepção, ou seja, as mediações culturais como tratam Martin-Barbéro (2001) e Garcia Canclini (1995), considerando que este último faz uma conexão direta da mediação do consumo na vida cultural.

Já o conceito de midiatização teria uma certa centralidade nos objetos midiáticos nas suas formas, estratégias de divulgar as marcas e que permitem o seu entendimento complementar no processo comunicacional, bem como o mapeamento de seus processos de produção de sentido por meio dos estudos de recepção, pois como já colocou Sousa (1994) a comunicação só ganha sentido, ao incorporar no seu processo de investigação o sujeito-receptor.

Desse modo, as reuniões de grupo de discussão com os adolescentes serão realizadas com base na perspectiva teórica daquilo que defendemos como sendo a 
A regulação na publicidade de cervejas junto ao público adolescente: problemáticas e caminhos da pesquisa comunicacional

enunciação da recepção publicitária e das práticas de consumo (Cf. TRINDADE, $2008)^{4}$. Reconhecemos que esta ação de pesquisa é uma contribuição nossa ao campo de investigação que já manifesta uma aplicação reconhecida em (TRINDADE, 2011 a e b), uma vez que, a área da comunicação publicitária ainda manifesta certa incipiência no campo dos estudos de recepção como apontam (JACKS e PIEDRAS, 2010).

E para os estudos de circulação nos fenômenos de comunicação transmidiáticos em mídias sociais entre os adolescentes, serão utilizados contribuições recentes da pesquisa nacional em comunicação conforme nos ajudam a pereceber discussões de (FAUSTO NETO, 2010) e (SCHIMT et al, 2011), que não necessariamente pensadas para no nosso objeto, mas que mostram um caminho fértil de aplicação em nosso estudo.

No primeiro caso o autor apresenta uma discussão sobre os avanços da recepção na perspectiva de poder registrar aquilo que antes era algo inapreensível, a circulação dos sentidos. Isso agora se torna possível graças ao advento das mídias sociais, que em função de sua natureza tecnológica, possibilita a formulação de novos protocolos para o mapeamento de manifestações e circulações de sentidos nesse novo panorama da recepção, isto é, o monitoramento e reflexão sobre as estratégias de circulação midiáticas. Já o segundo texto é uma aplicação do grupo liderado pela Pesquisadora Nilda Jacks no trabalho realizado pela equipe de Daniela Schimit e outros autores que apresentam, repaldados no texto de Fausto Neto (2010), uma sistematização quantitativa e qualitativa de dados referentes à circulação de informações nas mídias socias (facebook, orkut, twwiter) de receptores sobre a telenovela Passione.

Ademais, tornam-se fundamentais a este momento da pesquisa a ser empreendida os estudos de Trindade (2009) e de Barthes [1997 (1961)] sobre os sentidos midiatizados na alimentação, que podem ser adaptados a mediatização do consumo de cervejas. Esse conjunto teórico permite a reflexão sobre a discursivização social que o setor em estudo cria no cenário brasileiro.

Nesse sentido, para que sejam revelados os sentidos ideológicos vigentes na sociedade, refletidos pela publicidade, autores como Agnes Heller (1985) e Ecléa Bosi (1997) são de extrema importância, levando-se em conta que diversas vezes as

\footnotetext{
${ }^{4}$ A enunciação da recepção publicitária envolve o estudo de recepção no contexto de vida dos investigados. Como realizaremos grupos de discussão, as marcas desse contexto serão percebidas nas manifestações discursivas dos sujeitos. Daí a importancia de usarmos a análise de discurso crítica, para mantermos a coerência com a busca da produção de sentido da recepção em relação ao estudo citado.
} 
A regulação na publicidade de cervejas junto ao público adolescente: problemáticas e caminhos da pesquisa comunicacional

de Eneus Trindade

mensagens das marcas de cervejas trabalham estereótipos cristlizadores de percepções e comportamentos para o consumo aos vários públicos.

Quanto às práticas de consumo e aos rituais alimentares, referentes ao universo da midiatização das marcas cervejas, iremos trabalhar a noção de ritual dada em McCracken (2003: 114) e as adaptações dos rituias de consumo da moda proposta por este autor adaptadas ao setor alimentar elaboradas por (LLANO LINARES, 2010). Essa combinação nos permite verificar e criticar as práticas de consumo sugeridas nas campanhas a serem estudadas.

Por fim, este escopo de reflexão sobre a mediatização do consumo de marcas de cerveja será contrastado aos elementos dos estudos de efeitos, sobretudo os efeitos de percepção e impacto obtidos pelo procedimento do eye tracking, que pelos registros de trânsito, fixação do olhar permitirão explorar as conexões entre elementos cognitivos e culturais da apreensão dos efeitos de curto a longo prazo, como nos auxilia a leitura das teorias dos efeitos em comunicação propostas por (WOLF, 1999).

Por fim, outro aspecto importante abordado neste quadro teórico diz respeiro à necessidade de se discutir a regulamentação e regulação no setor de bebidas alcóolicas e as noções de comunicação do risco, contextualizados pelos trabalhos de Batista (2007) sobre a comunicação de risco; sobre o risco do consumo de bebidas alcóolicas por adolescentes como problema de saúde pública Pinsky (2009), bem como busca respaldo nos trabalhos de crítica à regulamentação do consumo de bebidas alcóolicas em (VENDRAME, 2010); (VENDRAME, et al, 2007); JONES (2000); (JONES, HALL, MUNRO, 2008) e (HASTINGS, 2000) e (MARTINS e MAGRO, 2008).

Além disso, o trabalho visa esclarecer, a partir do seu objeto de pesquisa, sobre a distinção entre regulação e regulamentação, assunto este pouco debatido no campo comunicacional, bem como busca revisar as discussões realizadas sobre o assunto da regulamentação do consumo e limites da comunicação de bebidas alcóolicas, promovendo uma leitura comparada entre as legislações do Brasil, de alguns países da Comunidade Européia, Inglaterra, Estados Unidos, Canadá e Autrália.

Com este breve quadro teórico acreditamos ser possivel o desenvolvimento de reflexões consistentes sobre a mediatização do consumo de cerveja, buscando nos diferenciar dos tradicionais e majoritários estudos discursivos de campanhas de cerveja, que apenas abordam as estratégias criativas para o posicionamento das marcas deste 
A regulação na publicidade de cervejas junto ao público adolescente: problemáticas e caminhos da pesquisa comunicacional

de Eneus Trindade

setor sem os devidos questionamentos com vistas às mudanças nas práticas sociais, por meio das práticas discursivas midiatizadas.

\section{CAMINHOS METODOLÓGICOS}

Diante do quadro teórico híbrido que apresentamos, classificamos esta pesquisa como um estudo pautado nos multi-métodos e assim, cabe esclarecer que se pretende analisar os materias midiáticos das marcas e publicidade, bem como o material gerado com os receptores e nos estudos de impacto/efeitos com os seguintes procedimentos:

Levantamento de artigos na intercom e de teses em comunicação no banco de dados da Capes sobre os estudos de campanhas de cervejas;

Levantamento de artigos internacionais sobre a temática do projeto;

Levantamento de campanhas publicitárias impressas e televivas veiculadas entre 2008 e 2011, identificando: anunciante, agência; veículo; abordagem temática das peças e conceito de posicionamento das marcas na campanha;

Análise semiótica de fundamentação em Peirce (1977) das peças publicitárias e demais expressões das marcas de cervejas. Pretende-se extrair desta mirada teóricometodológica o percurso analítico que dará suporte para a construção do universo de sentido da cerveja e também para proceder à análise das expressões das marcas de cerveja selecionadas. Sobre este aspecto serão escolhidas as marcas de maior presença mercadológica (market-share) e as de maior investimento publicitário na última década. A metodologia "Universo de sentido", parte da análise do conceito que se pretende gerar/comunicar, no caso, "Universo da cerveja", para então entender e construir o contexto sígnico referencial (cores, linhas, formas, texturas, ícones, palavras, sons, sabores, aromas etc.) que lhe dará suporte na cultura estudada. O protocolo de análise, derivado das três categorias de pensamento peirceanas, está sinteticamente apresentado a seguir: 1 - Profundidade do conceito 1.1. Campo de significação da cerveja; 1.2. Camadas adicionais de significação da cerveja; 1.2.1. camada conotativa (sentidos metafóricos); 1.2.2. camada simbólica (o que a cerveja pode simbolizar). 2 - Extensão do conceito; 2.1. Universo referencial da cerveja; 2.2.1. universo das coisas/objetos/práticas a que a cerveja está vinculada ; 2.2.2. universo das coisas que podem causar. 3 - Interpretação do conceito. (Ver SANTAELLA, 2002 e PEREZ, 2004); 
A regulação na publicidade de cervejas junto ao público adolescente: problemáticas e caminhos da pesquisa comunicacional

de Eneus Trindade

Análise crítica do discurso com: identificação do plano representacional. Ideologias, estereótipos, padrões hegemônicos dos valores contidos nas campanhas e tratamento das noções de risco pelas mesmas; Identificação dos elementos do plano identificacional e do plano acional com base nos rituais de consumo de cerveja sugeridos nas campanhas. (FAIRCLOUGH, 2001 e 2003); (LLANO LINARES, 2010);

Identificação dos tipos de mediatização das marcas de cervejas em campanhas publicitárias, suas mediações e regulações no processo de construção da discursivização social sobre o consumo de cervejas, junto aos adolescentes. (BRAGA, 2006) e (CASAQUI, 2011);

Contraste com base nas discussões do grupo de adolescente, sobre a noção de risco da comunicação (BATISTA, 2007) e nas questões de regulação e regulamentação em que medidas as práticas discursivas das campanhas de cerveja sugerem ou não mudanças sociais ou reafimam a reprodução de práticas sociais vigentes (TRINDADE, 2008 e 2011a);

Grupos de discussão (estudo de recepção publicitária e consumo e levantamento de hipóteses sobre os efeitos de percepção), a ser realizado com adelescentes de 15 a 17 anos da rede estadual de Ensino de São Paulo. Tais encontros buscam identificação das mediações (Cf. MARTIN-BARBERO, 2001 e GARCIA CANCLINI, 1995) na formação do consumo destes jovens (religião, escola, familia, entre outros aspectos possíveis), como também visam à exibição e comentários sobre as peças publicitárias de cervejas. Levantamento da percepção dos jovens sobre as questões de risco no consumo de bebidas alcóolicas e dos elementos de maior impacto percebidos, subsidiando o trabalho de hipóteses para os estudos dos efeitos, utilizando o procedimento do eye tracking.Estudos dos efeitos serão realizados com estudantes (em sessões individuais, pois o equipamento deve ser calibrado ao olhar de cada sujeito participante da pesquisa) para os estudos de percurso de olhar pelo instrumento do eye tracker, na visualização de mensagens publicitárias. Os resultados dessa observação serão cruzados com os levantamentos descursivos. Cabe observar que, se não houver subsídio financeiro suficiente para a compra deste equipamento. O estudo dos efeitos ficará restrito à manifestação de suas hipóteses na conclusão deste trabalho.

\section{CONSIDERAÇÕES FINAIS}


A regulação na publicidade de cervejas junto ao público adolescente: problemáticas e caminhos da pesquisa comunicacional

de Eneus Trindade

O trabalho de pesquisa foi iniciado em dezembro de 2011 e a ser finalizado em novembro de 2013. Portanto, ainda estamos no início dos trabalhos de pesquisa. De todo modo, existe no horizonte de contribuições da pesquisa dois grandes eixos de resultados.

O primeiro deles, de natureza empírica, busca por um conjunto de procedimentos quantitativos e qualitativos, gerar a triangulação de dados entre estudos dos efeitos, análise da recepção e estudos de circulação transmidiáticos para discussão do tipo de efeitos e apropriação de sentidos que os signos do universo publicitário das cervejas podem operar junto aos adolescentes em suas práticas de sociabilização pelo consumo. Tal aspecto manifesta o sentido de pioneirismo e inovação deste trabalho no campo da pesquisa comunicacional brasileira, dentro da área de publicidade, sempre pensada de forma tímida, centrada nos estudos das mensagens, principalmente. Este trabalho, sem negar esta tradição, busca ir além.

O segundo eixo, refere-se às contribuições teóricas resultantes da pesquisa que deve abrir caminhos para o entendimento geral do que deva ser a regulação em comunicação e o pensar, quem sabe, suas políticas e seu marco regulatório, a partir do objeto de estudo (o sistema publicitário cervejeiro e suas interferências no consumo do público adolescente). Tal perspectiva deve se opor a visão menor de regulamentação das práticas mídiáticas comerciais, que estão sempre sujeitas a obsolescência em função dos fenômenos da midiatização social que geram inúmeras formas de publicização, na dinâmica vigorosa de renovação do sistema publicitário.

O olhar das Ciências da Comunicação sobre a questão proposta pela pesquisa deve, por fim, buscar relativizar a idéia superada dos estudos dos efeitos de curto prazo que, de certa forma, vigora em áreas como Direito e a Saúde Pública no seu pensar sobre as práticas e usos midiáticos, pois normalmente tais áreas desconhecem os meandros destes fenômenos na vida cultural cotidiana, daí o reducionismo de recomendar a proibição da comunicação para acabar com os problemas de saúde pública, por exemplo, como se sugere na atualidade para a questão da cerveja e como já foi feito com as campanhas de cigarros. Os problemas citados não se resolvem nessas ações de interdição, pois essa equação não é verdadeira e daí vem o desafio que nos move com esta pesquisa.

A regulação de sentidos da comunicação passa por uma política pública do uso educacional das mídias, para gerar conteúdos que visam o estímulo e a constituição, 
A regulação na publicidade de cervejas junto ao público adolescente: problemáticas e caminhos da pesquisa comunicacional

de Eneus Trindade

bem como a preservação, da participação cidadã no mundo cultural midiatizado. Regulação não é só regulamentação. E necessariamente a regulamentação da comunicação com interdições, não é a regulamentação do consumo produtos. Existem hiatos nesses processos. Portanto, a questão é complexa e envolve as noções de: políticas reguladoras e marcos regulatórios; regulação de setores; regulação da economia/mercados; regulação de consumo e regulação de sentidos socioculturais; A regulação da comunicação é a regulação de um setor de atuação ampla na perspectiva dos sentidos socioculturais de um dado contexto, frente às suas pretensas ações de políticas educacionais para a constituição de seus cidadãos. Isto é, regular significa chegar a um patamar civilizatório para dizer dentro de uma democracia participativa, que tipo ou modelo de sociedade queremos. A questão é complexa e definitivamente não se restringe a ideia de regulamentação.

\section{REFERÊNCIAS BIBLIOGRÁFICAS}

AMBEV (American Beverage Company) Disponível em <http://www.ambev.com.br/pt-br > Acesso em 20 jan. 2011.

AUSTIN, E. HUST, S. Targeting adolescents? The content and frequency ofalcoholic and beverage ads in magazine and video formats. Journal of Health Communication. v. 10. n.8, 2005: 769-785.

AUSTIN, E; CHEN, M. J; GRUBE, J.W. How does alcohol advertising influence underage drinking? The role of desirability, identification and skepticism.Journal of Adolescent Health. v. 38. n.4, 2006: 376-384.

BARTHES, R. Toward a psychosociologie of contemporary food consumption. In COUNIHAN, C. e VAN ESTEIK, P. Food and Culture: a reader. London: Routledge. 1997 : 20-27. Publicação original Vers une psico-sociologie de l'alimentation. In Annales. Paris: E.S.C.n.5. set-out.1961 : 997-986.

BRAGA, J. L. Sobre «mediatização » como processo interacional de referência. In Anais XV Encontro Anual da Compós. Bauru: UNESP/COMPÒS. 2006. GtComunicação e Sociabilidade.

BRAUDEL, F. Alimentation et categories de l'historie. In Annales, Paris: E.S.C.n16.1961: 623-728

CARNEIRO. H. Comida e sociedade. Rio de Janeiro: Ed.Campus.2003. 
A regulação na publicidade de cervejas junto ao público adolescente: problemáticas e caminhos da pesquisa comunicacional

de Eneus Trindade

CARVALHO, M. Regulação da propaganda- Liberdade de expresssão comercial? Isso não existe! Radis - Comunicação em Saúde. n.73. 2008: 8-11.

CASAQUI, V. Por uma teoria da publiciazação: transormações no processo publicitário. In Anais do XXXV Congresso Brasileiro de Ciências da Comunicação/INTERCOM. Recife: UNICAP/INTERCOM. 2011. NP Publicidade e Propaganda. CD-Rom.

CASSWELL, S; ZHANG, J. Impact of linking for advertising and brand allegiance on drinking and alcohol - related aggression: a longitudinal study. In Addiction. V. 93, n. 8. 1999: 1209-1217.

CHOULIARAKI, L; FAIRCLOUGH, N. Discourse in late modernity. Rethinking critical discourse analysis. Edinburgh: Edinburgh University Press.1999.

COLLINS, R. L; ELLICKSON, P. L; McCAFFREY, D. Harbarsoomians K. early adolescent exposure to alcohol advertising and its relationship to underage drinking. Journal of Adolescent Health. v. 40. n.6. 2007: 527-534

CONSELHO DE AUTORREGULAMENTAÇÃO PUBLICITÀRIA. Código de autorregulamentação publicitária. Disponível em http://www.conar.org.br Acesso em 05 de outubor de 2011.

BATISTA, L. Comunicação de Risco. In PEREZ, C. e BARBOSA, I.S. Hiperpublicidade 2. Cengage Learning. 2007: 429-447.

BOSI, E. A opinião e o estereótipo. In: Revista Contexto, nº 2, mar. 77, 1997: 97-104.

CARNEIRO, H. Comida e sociedade: uma história da alimentação. São Paulo: Campus. $7^{\mathrm{a}}$ edição. 1998.

Di NALLO. E. Meeting Points. Marketing para uma sociedade complexa. São Paulo:Cobra, 1999.

ELLINCKSON, P.L; COLLINS, R.L; HAMBARSOOIANS, K; McCAFFREY, D. F. Does alcohol advertising promote adolescent drinking? Results from a longitudinal assentement. In Addiction. v.100. n. 2. 2005: 235-246.

FAIRCLOUGH, N. Discurso e Mudança social. Brasília: UNB.2001

FAIRCLOUGH. Analysing discourse: textual analysis for social research. London:

Routledge. 2003.

FAUSTO NETO, A. As bordas da Circulação. In Revista Alceu. Rio de Janeiro:

PPGCOM/PUC-RJ. v. 10, n. 20, jan a jun. 2010: 55-69. 
A regulação na publicidade de cervejas junto ao público adolescente: problemáticas e caminhos da pesquisa comunicacional

de Eneus Trindade

FLANDRIN, J. L e MONTANARI, M. História da Alimentação. São Paulo: Estação

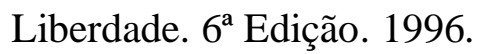

FLEMING, K; THORSON, E; ATKIN C.K. Alcohol advertising exposure and perceptions: links with alcohol expectancies and intentions to drink or drinking in underage youth and young adults. In Journal of Health Communication. v. 9. n.1. 2004: 3-29.

FLOCH, Jean-Marie. Semiotics, Marketing and Communication: Beneath the Signs, the Strategies, translated by Robin Orr Bodkin, New York: Palgrave Macmillan, 2005.

GARCIA CANCLINI, N. G. Consumidores e cidadãos: conflitos multiculturais da globalização. Rio de Janeiro. Ed. UFRJ, 1995.

GRUBE, J. Alcohol advertising: what are the effects? In National Institut On Alcohol Abuse and Alcoholism. Alcohol and Health: highlights from current research cap. 07. 2000: 412-426.

HASTINGS, G. Marketing alcohol to young people: implications for industry regulation and research policy. In Addiction. V.95. supl. 4: s597-s608. 2000.

HASTINGS, G; ANDERSON, S; COOKE, E; GORDON, R. Alcohol marketing and youth people's drinking: a review of the research. In Journal of Pubçlic Health Policy.v. 26. n.3. 2005: 296-311.

HELLER, A. Sobre preconceitos. In: $O$ cotidiano e a história. Rio de Janeiro: Paz e Terra, 1985.

HOLT, Douglas. How Brands Become Icons: The Principles of Cultural Brandin.

Cambridge: Harvard University Press, 2005.

JACKS,N. e PIEDRAS, E. R. A recepção da publicidade. Um campo incipiente. Análises de pesquisas produzidas entre 1990 a 2009. In TRINDADE, E. PEREZ, C (org.). I Pró-Pesq PP-Encontro Nacional de Pesquisadores em Publicidade e Propaganda. São Paulo: Schoba/ ABP2/ECA/USP/FAPESP. 2010: 191-210. Ebook:http://www.eca.usp.br/departam/crp/cultext/propesq/downloads/ebook_Pro pesq_pp.pdf.

JERNIGAN, D.H. The global expantion of alcohol marketing: ilustrative case studies and recommendations for action. In Journal of Public Health Policy. v.20, n.1. 1999: 56-80. 
A regulação na publicidade de cervejas junto ao público adolescente: problemáticas e caminhos da pesquisa comunicacional

JONES, S.C. The decline of ethics or the failure self-regulation? The case of alcohol advertising. Visionary marketing for 21th Century: facting the chalange. 2000: 595-599.

JONES, S. C; HALL, D; MUNRO, G. How effective is the revised regulatory code of alcohol advertising in Australia? In Drug and alcohol Review. v.27, n. 1, 2008: 29-38.

LARANJEIRAS, R; PINSKY, I; ZALESKI, M; CAETANO, R. I Levantamento Nacional sobre padrões de consumo de álcool na população brasileira. SENAD ( Secretária Nacional de Políticas Sobre Drogas e Álcool. 2007.

LLANO LINARES, N. Transferência simbólica de significados no sistema alimentar. In TRINDADE, E. PEREZ, C (org.). I Pró-Pesq PP-Encontro Nacional de Pesquisadores em Publicidade e Propaganda. São Paulo: Schoba/ ABP2/ECA/USP/FAPESP. 2010: 191-210. GT- Propaganda e Linguagens. Ebook:

http://www.eca.usp.br/departam/crp/cultext/propesq/downloads/ebook_Propesq_pp.pdf. MARTIN-BARBERO, J. Dos meios às mediações. Rio de Janeiro. Ed. UFRJ, 2001.

MARTINS, P.L; MAGRO, M. Liberdade de expressão publicitária. Uma falsa discussão. In Observatório da imprensa. São Paulo. 2008. Disponível em http:// www.observatoriodaimprensa.com.br. Acessado em julho de 2008.

McCRACKEN, G. Cultura e consumo. Novas abordagens ao caráter simbólico dos bens e das atividades de consumo. Rio de Janeiro. Ed. Mauad. 2003. Trad. Fernanda Eugênio. Coleção Cultura e Consumo coordenada por Everardo Rocha.

MICK, David Glen \& OSWALD, Laura. The Semiotic Paradigm on Meaning in the Marketplace. In Handbook of Qualitative Research Methods in Marketing, Russell W. Belk, editor, Northampton: Edward Elgar Publishing, 2007.

OSWALD, Laura. Semiotics and Ethnography: Leveraging Research to Build Brand Strategy and Advertising for the African American Segment. In Proceedings from the Annual Conference of the Advertising Research Foundation, 2006.

PEIRCE, Charles. Semiótica. São Paulo: Perspectiva, 1977.

PEREZ, C. Os signos da marca. Expressividade e sensorialidade. São Paulo. Thomson Learning, 2004. 
A regulação na publicidade de cervejas junto ao público adolescente: problemáticas e caminhos da pesquisa comunicacional

de Eneus Trindade

PINSKY, I. Publicidade de bebidas alcóolicas $e$ os jovens. São Paulo: UNIFESP/FAPESP. 2009.

PINSKY, I; JUNDI, S. E. O impacto da publicidade de bebidas alcóolicas sobre o consumo entre jovens: revisão de literatura internacional. In Revista Brasileira de Psiquiatria. v. 30.n.4. 2008: 362-374.

PINSKY, I; SILVA, M.T. A frequency and content analisys of alcohol advertising on brasilian television.In Journal of studies on alcohol. v.60, n.3. 1999: 394-399.

SAFFER, H. Alcohol advertising bands and alcohol abuse: an international perspective. In Journal of Health Economics. n. 10. 1991: 65-79.

SAFFER,H; DAVE, D. Alcohol advertising and alcohol consumption by adolescents. In Journal of Health Economics.v. 15. n. 6, 2006: 617-637.

SANTAELLA, L. Semiótica Aplicada. São Paulo: Thomson Learning. 2002.

SANTAELLA, Lucia. Teoria Geral dos Signos. São Paulo: Cengage, 2001

SCHMITZ, D; OIKAWA, E; SIFUENTES, L; PIENIZ, M. O consumo e a circulação da Telenovela Passione num cenário multiplataforma. In Anais XX Encontro Anual da COMPÓS, Porto Alegre: UFRGS/COMPÓS. 2011. GT- Recepção: processos de interpretação, uso e consumo midiáticos.

SINDIVERV - Sindicato Nacional da Indústria da Cerveja. Mercado. 2002/2003. Disponível em: 〈http://www.sindicerv.com.br/mercado.php>. Acesso em: 20 jan. 2011.

SNYDER, L, B; MILICI, F.F; SLATER, M; SUN, H; STRIZHAKOVA, Y. Effects of alcohol advertising exposure on drinking among youth. In Arch Pediatr Adolesc Med. v. 160, n.1, 2006: 18-24.

SOUSA, M. W. Sujeito, o lado oculto do receptor. São Paulo: Brasiliense. 1994.

SOUZA, Jorge Pedro Elementos de Teoria e Pesquisa da Comunicação e dos Media. $2^{\text {a }}$ edição revista e ampliada. Portugal: Porto. 2006.

TRINDADE, E. A produção de sentido na recepção da publicidade e nas práticas de consumo de alimentos na cidade de São Paulo. São Paulo/Brasília. GESC3/ECA/USP/CNPq. Junho. 2011a. Relatório Final de Pesquisa financiada pelo Edital Universal CNPq 02/ 2009 Ciências Humanas.

TRINDADE, E. Consumo alimentar familiar e publicidade: a recepção na perspectiva da ADC In Anais XX Encontro Anual da COMPÓS, Porto Alegre: 
A regulação na publicidade de cervejas junto ao público adolescente: problemáticas e caminhos da pesquisa comunicacional

UFRGS/COMPÓS. 2011 b. GT- Recepção: processos de interpretação, uso e consumo midiáticos.

TRINDADE, E. Semiótica e Publicidade de Alimentos: uma revisão teórica e aplicada. Revista Pensamento \& Realidade. São Paulo: PPGADM/PUC-SP. v. 24. n.2. 2009: 29-46.

TRINDADE, E. Recepção Publicitária e Práticas de Consumo. In Revista Fronteiras. Estudos Midiáticos. São Leopoldo: PPGCOM/UNISINOS. v. X n.11: 73-80.

UMIKER-SEBEOK, Jean. Marketing and semiotics: Selected papers from the

Copenhagen symposium (Studies from the Marketing Institute), Berlin: Mouton de Gruyter, 1987.

VENDRAME. A. Propaganda de cerveja na televisão brasileira: avaliação das violações do código de auto-regulamentação.São Paulo: UNIFESP.2010. Tese (Doutorado em Psiquiatria).

VENDRAME, A; PINSKY, I; FARIA, R; SILVA, R. BABOR, T. Assessment of selfregulatory code violation in brazilian televison beer advertisements. Em Avaliação pelo Journal of studies on alcohol. Aceito para apresentação no 33rd Annual Alcohol Epidemiology Symposium of the Kettil Brunn Society (KBS) for Social and Epidemiolocal Research on alcohol. 2007/2008.

WOLF, M. Teorias da Comunicação. Mass media contexto e paradigmas. Novas tendências. Efeitos a longo prazo. O newmaking. Lisboa: Presença. 1999.

WORLD HEALTH REPORT. Reducing risk, promotion healthy life. World Helath Organization. 2002.

Artigo submetido: outubro de 2012

Artigo aprovado: dezembro de 2012 